\title{
E-learning as a Veritable Tool for Capacity Building in Adult Education and Open Distance Education in Nigeria
}

\author{
Owede, Kosioma Eli \\ Adult and Non-Formal Education, School of Education, Federal Colege of Education (T), PMB 11 Omoku, Rivers State \\ Kosede2006@yahoo.com.
}

Doi:10.5901/jesr.2015.v5n1p137

\begin{abstract}
Adult education as a discipline has continued to play its role by providing, equipping and sustaining the needed manpower required by developing societies to improve themselves by making the adult working population functional. It uses open and distance learning as one of its effective tools. These roles can be improved by using e-learning training designs and techniques that have open the learning space and broken the barriers of distance to all through modern technology. This paper examined the concept of e-learning, scope and objectives of adult education, Open and Distance Learning (ODL). But e-learning designs and techniques have not been fully explored due to inadequate availability of electricity and internet facilities with high level of computer non-compliance adults and illiteracy among the adult population. These hurdles can be overcome by providing the appropriate Information and Communication Technology (ICT) facilities with the formulation of enabling policies and sensitization of the adult population.
\end{abstract}

Keywords: E-learning, Adult, Education, Distance, Open-learning.

\section{Introduction}

Adult education has Open and Distance Learning (ODL) as one of its pivotal tools to increase adult functionality by improving adult potentials and skills. Distance learning systems existed over the years and have been relevant in adult and continuing education programmes empowering the adults. Its relevance stem from convenience and ease of learning. Open Distance Learning (ODL) programmes holds a beam of hope rays for the adult learning population to keep them at par with the present day realities. The open nature grant the individual learner the choice of one or more learning process and the adoption of relatively flexible organization structures, delivery and communication patterns and the use of technology in supporting learning. Here lies the importance of e-learning as adults learners have often before now been faced with various learning problems due to their nature as adults, who are faced with various economic, social; physical, psychological, cultural and political hurdles with time as the greatest challenge. E-learning by its architectural learning and training design has introduced a new hope by removing and demystifying the tyranny and hurdles of distance, space and location that were once barriers due to the peculiar geographical features of Nigeria. This work employed the descriptive approach, anchoring on the conceptual framework methodology, seeks to bring to fore the pivotal role of e-learning in improving adult education through distance learning in the nation's quest to increase the literate functional adult population, improve and update the functional skills of the adult working population and others within the society that were unable or deprived from formal education.

\section{Concept of E-Learning}

E-learning simply means electronic learning and as usual for any concept, e-learning has been defined differently based on different school of thought. The definition of e-learning is classified into four namely, internet and network based, eccentric based, framework based and electronic based. Internet base definition sees e- learning as training that is delivered partially or entirely through electronic hardware, software, or both, while the frame work based definition sees e-learning as the use of innovative technologies and learning models to transform the way individuals and organizations acquire new skills and access knowledge (Moeng, 2004). It is a collaboration of information, interaction, collaboration, and in-person. To Rosenberg (2001) , e-learning is the use of internet technologies to _deliver a broad array of solutions that enhance knowledge and performance based upon the three fundamental criteria of network, delivery to the end-user via a computer using standard internet technology and focuses on the broadest view of learning. E-learning covers a 
wide array of activities from supported learning, to blend or hybrid learning which is the combination of traditional and elearning practices. It is Web-based training (WBT), and on-line learning, which is training that, resides on a server or host computer that is connected to the World Wide Web. Rossett (2001). Adrich (2004), sees e-learning as: a broad combination of processes, content, and infrastructure to use computers and networks to scale and/or improve one or more significant parts of a learning value chain, including management and delivery.

For the eccentric base, e-learning is everything training which is the tools for managing, modularizing and handling different kinds of content and learning objects ( electronic and non-electronic forms, and traditional classroom instruction), asynchronous learning, such as virtual labs, virtual classrooms and collaborative work spaces, simulations, document repositories and publishing programs, tools for prescribing learning, managing development pathways and goals and handling e-commerce and financial transactions related to learning., and the utilities and capabilities for supporting informal learning, mentoring, communities of practice and other non-training interventions.

E-learning as a medium for delivering learning like other medium has its advantages and disadvantages, some of the advantages include:- Scheduling classwork around personal and professional work, resulting in flexible learning, Reduces travel cost and time to and from school, Learners privilege of selecting learning materials that meets their level of knowledge and interest, Learners ability to study wherever they have access to a computer and Internet, Provision of Self-paced learning modules allowing learners to work at their own pace, Flexibility to joint discussions in the bulletin board threaded discussion areas at any hour, or visit with classmates and instructors remotely in chat rooms, Different learning styles are addressed and facilitation of learning occurs through varied activities, Development of computer and Internet skills that can be applied in other fields., The building of self-knowledge and self-confidence and encouraging students to take responsibility for their learning. While its disadvantage are, Unmotivated learners or those with poor study habits may fall behind, Lack of familiar structure and routine may take time getting used to, Students may feel isolated or miss social interaction thus the need to understanding different learning styles and individual learner needs, Instructor may not always be available on demand, Slow or unreliable Internet connections can be frustrating, Managing learning software can involve a learning curve. Summarily e-learning is cost effective, faster in delivery, environment friendly, saves time and is effective among others.

\section{Adult Education}

Adult education is the process whereby adults engage in systematic and sustained learning activities in order to gain new forms of knowledge, skills, attitudes, or values. Adult education can take place in the workplace, through extension schools, colleges and universities, and lifelong learning centers including training and development as professional development. Adult Education has been defined as all educational programmes aimed at improving the cognitive, psychomotor and affective domains of people who are recognized by their societies as adults. It permeates all levels of education, and concerns itself with everything that affects the wellbeing of the entire citizens and their societies. Ihejirika and Onyenemezu, (2012), quoting Houle (1976,) defined adult education as: The process by which men and women (in groups or in institutional settings) seek to improve themselves or their society by increasing their skills, their knowledge or their sensitiveness; any process by which individuals, groups or institutions try to help men and women improve in these ways. While (Olumukoro 2005) citing UNESCO (1976) described adult education as: The entire body of organized educational process whatever the content, level and method, whether formal or otherwise, whether they prolong or replace initial education in schools, colleges and universities, as well as in apprenticeship, whereby persons regarded as adults by the society to which they belong, develop their abilities, enrich their knowledge, improve their technical or professional qualifications and bring about changes in their altitudes or behaviour in the two-fold perspectives of full personal development and participation in balanced and independent social, economic and cultural development. Adult Education is an organized and sequential learning experiences designed to meet the needs of adults. It is developmentoriented, being a programme that is geared towards making adults to be more useful to themselves and society. Adult education in an emancipating sense is motivated by the wants and needs of its target group, and as such requires a participatory form of program selection and organization, in other words, active involvement on the part of the participants in the choice of topics and methods for their learning.

This can occur in a formally structured learning situation, or through individual or group action, provided the clients are afforded the opportunity to analyze their conditions and become conscious of the course and outcome of their actions. This need to become increasingly self-reliant in adult education, as in other aspects of development, will have to be reflected in the organization of adult education activities. Obviously there is no 'ideal' adult education organization pattern to which all nations could, or should, aspire. 


\subsection{Scope of Adult Education}

Adult education as a field/branch of education encompasses all activities carried out by adults to improve themselves and contribute to national development. It is classified as, education for vocational, technical, and professional development, education for health, welfare and family, education for civic, political, and community competence, education for "selffulfillment, remedial, fundamental and literacy education, which serves as a prerequisite for all other kinds of adult education. The Federal Government of Nigeria (2004) articulates the objectives of adult and non-formal education in the National Policy on Education to include:

- Provision of functional literacy and continuing education for adults and youths who never had the advantage of formal education or who did not complete their primary education.

- Provision of functional and remedial education for young people who prematurely dropped out of formal school system.

- Provision of further education for different categories of completers of the formal education system in order to improve their basic knowledge and skills.

- Provision of in-service, on-the-job, vocational and professional training for different categories of workers and professionals in order to improve their skills and competence.

- Give the adult citizens of the country necessary aesthetic, cultural and civic education for public enlightenment (FRN, 2004, 19).

In Nigeria adult education is seen as a tool for national development and covers the following:-

- Basic Literacy Programme: This is a programme designed for illiterates to enable them acquire the basic skills of reading and writing.

- Post Literacy Programme: This is a programme for completers of Basic Literacy Programmes and drop outs from formal primary schools to upgrade their knowledge.

- Women Adult Education Programme: Designed to improve the services of literate and illiterate women in the society.

- Distance Education Programme: Designed for those who are unable to enroll in the regular or formal educational system. The medium of instruction is by correspondence, radio or television and any other medium that makes it possible for the student and facilitators to interact.

- Sandwich Programme: Organized for adults who stay in other commitments for most of the year and come into residence in their various schools when they can afford it.

- Nomadic Education Programme: For cattle rearers who do not settle in a place because they have to follow their herds of cattle around in search of grazable pasture. They do not receive formal education. Mobile Education Programme has been established to take care of this unfortunate situation.

\subsection{Adults learning principles and theories.}

Adults are involved in the world of work contributing to the socio-political and socio-economic development of themselves and the nation. Because of their nature, they need knowledge and information for immediate use, a core principle in the practice of adult education. This therefore requires a distinct teaching and learning principle. Andragogy fits in here to propel the adults into acquiring the necessary skills for themselves and society. Andragogy as the art and science of helping adults to learn operates on five assumptions which are that adults:-

- Has an independent self-concept and can direct his or her own learning.

- Has accumulated a reservoir of life experiences that is a rich resource for learning.

- Has learning needs closely related to changing social roles

- Learning needs is problem-centered and interested in immediate application of knowledge

- Are motivated to learn by internal rather than external factors (Merriam, 2001, p.5)

These assumptions fits properly in the modus operandi of e-learning, since adults do not have the luxury of time, they can through e-learning, learn anywhere either at home, office, hotel room etc. Base on the working principles of andragogy, which are that, adults need to be involved in the planning and evaluation of their instruction, experience (including mistakes) provides the basis for learning activities. Adults are most interested in learning about subjects that have immediate relevance to their job or personal life and adult learning is problem-centered rather than content-oriented can be facilitated better through e-learning. Efficiency is a key index for the functionality of adults in their daily activities, 
which can be achieved through lifelong learning, involving constant acquisition and upgrading of skills and knowledge. They therefore do not need to be jumping from classroom to working environment, rather can be done through all the opportunities and avenues provided by e-learning.

Two key theories that help adult learning in open distance education are experiential and self- directed learning. Experiential learning is a learning theory that is learner-centered and operates on the premise that individuals learn best by experience, "learning by doing". Experiential learning thus has the learner directly involved with the material being studied instead of just thinking and talking about that material. It is summarized as "Tell me, and I will forget. Show me, and I may remember. Involve me, and I will understand." It is a cyclic process involving setting goals, thinking, planning, experimenting and making decisions, and finally action, followed by observing, reflecting and reviewing. It uses participants' own experience and their own reflection about that experience, rather than lecture as the primary approach to learning. Experiential learning theory allows for the generation of understanding and allows for the transfer of skills and knowledge. It involves doing something and discovering what it is like, how it made the learner feel, what it meant to the learner. Experiential learning is their (adults) experience and no one else's It is therefore, particularly effective in adult education as it addresses the cognitive, emotional and the physical aspect of the learner. Experiential learning theory builds on experience. This is especially important in adult learning because simply by living, adults bring a wealth of experience to every learning situation. A holistic learning approach is effective when the learning has intrinsic motivation which is a common characteristic in adult learning.

Self-directed learning in an informal learning defined as the process in which individuals take on the responsibility for their own learning process by diagnosing their personal learning needs, setting goals, identifying resources, implementing strategies and evaluating the outcomes. Informal and incidental learning is at the heart of adult education because of its learner-centered focus and the lessons that can be learned from life experience

The three categories involve in self-directed learning are the goals, the process, and the learner. In an adult learning context, the goals are generally self-determined, as is the process. Self-directed learning can be enhanced with facilitation, particularly through providing resources. Motivation is key to a successful self-directed learning experience.. Adult Learners are motivated by the opportunity to gain new skills, knowledge, and attitudes to improve their work performance and Improve family life and health, enjoy the arts and physical recreation, participate in a hobby, or simply increase their intellectual capital. It can be integrated with daily routines triggered by an internal or external motivation while serving as an inductive process of reflection and action linked to learning of others.

\section{Distance Education}

Distance education also referred to as distance learning, or D-Learning is a mode of delivering educational instruction to students that are not physically present in a traditional classroom setting on an individual basis. Barikor, (2003), sees distance education as the art of bringing both the teaching and learning elements through a multimedia education process in the situation where the teacher and the learners may never meet. It involves the two peculiar characteristics of the development of a subsystem (distance teaching) and a student support subsystem (distance learning). It is anchored on Carl Rogers philosophy of social ideals for liberal education, which believes that "nobody should be denied the opportunity to learn because he is poor, geographically isolated, socially disadvantaged, in the state of poor health, institutionalized or unable to place himself in a school environment for learning" This is because education is for self actualization for man to become a fully functioning person.

Some of the elements of distance education are:-

- Industrialization of teaching and learning.

- Provision of two-way communication.

- Possibility of occasional meting for both didactic and socialization.

While it values as summarized by Nwizu (2001:25) are:-

- The provision of equal opportunity for education.

- Liberalization and democratization of education.

- Meeting the high demand for higher education.

- Achievement of education for all.

- Increasing access to education.

- Increasing the supply for needed manpower.

- Providing opportunity for work study and

- Cost reduction of education. 
Distance learning provides access to learning with the source of information and the learners separated by time and distance, or both. It operates on the principles of learner centeredness, lif-long learning, flexibility of learning, removal of barriers to access learning, recognition for credit of prior learning, provision of learners support facilities and the construction of learning programmes in the expectation that learners will succeed. Distance education is a field of education using educational strategies that take advantage of technology to deliver lessons to students without requiring them to be in a traditional educational classroom setting.

Distance education courses that require a physical on-site presence for any reason (including taking examinations) have been referred to as hybrid or blended courses and Massive Open Online Courses, (MOOCs), aimed at large-scale interactive participation and open access via the web or other network technologies, are a recent development in distance education. It also use Interactive Radio Instruction (IRI), Interactive Audio Instruction (IAI), online virtual worlds, digital games, webinars, and webcasts, all of which are referred to as e-learning. In the present day it is also referred to as Distance e-Learning or DeL, which is the combination of Distance Education and e-learning characterized by the extensive use of information and communication technology (ICT) in the delivery of education and instruction and the use of synchronous and asynchronous online communication in an interactive learning environment or virtual communities, in lieu of a physical classroom, to bridge the gap in temporal or spatial constraints. Distance e-Learning combines the strengths and advantages of Distance Education and e-learning. "The focus is shifted to the education transaction in the form of virtual community of learners sustainable across time.

\subsection{Building and designing E-learning for Adult Education, Open and distance learning.}

E-learning and distance education can play significant roles in helping adults become integrated with the rest of society and become functional. Demographic and cultural changes affect adults in society thus, online learning programs become increasingly appealing to them, with the dynamic nature of society that requires continuous learning. Adult education programmes are client centered base on the needs of the clients, therefore the paragogy theory as opined by Corneli and Danoff, (2011), that online environments are now sufficiently developed to support peer production of content which can be shared freely and widely, thus promoting learning for all within any given community. The learners frame work design developed by Moggridge (2007) that is geared towards developing web interactions by showing a person's needs and behavior for a particular project or task. It could be used to target the needs of learners as a two-by-two matrix consisting of the pathfinder, organizers, onlookers and daydreamers. The learning platform serves as a veritable tool to design adult education, open and distance learning programmes that is made up of four main approaches to Interaction Design which are the Performance or Activity-Centered Design, Guru or Genius Design, Learner or User-Centered Design and System Design. The performance centered design which focuses on the tasks that are composed of actions and decisions that the learners need to perform and learner centered design that focuses on the needs and goals of the learners who guide the design; while the Learning Designer aids with the content and awareness, all these suits adult education principles. It is based on the concept that adults know what their needs, preferences, and goals, thus they can collaborate throughout every stage of the learning design process to build the objectives and content base on their felt needs. The various design models of e-learning instructions when applied in adult education programmes will be the grease that lubricates the wheel of progress.

E-learning courses are an intrusion to the natural learning process. With good planning, it's a welcome intrusion because it can compress time and create cost-effective and repeatable learning events. Therefore the following will help in the building of an e-learning course for adults in open distance learning programme

- Set clear expectations and objectives. Let them know why they're taking the course and what they should be learning

- Adult learners don't like to fail. and they don't like to fail publicly. Make it clear when they are being tested and when they aren't.

- Create free environment. Let them click around and explore.

- Provide ways to collect information. Create situations where they need to make decisions by allowing free collection of information needed to make decisions. This is a much better way to assess understanding than viewing a screen full of text.

- Focus on relevance. Adult learners need information they can use now, therefore give them what they can use and not store. Guard against the banking concept.

- Create a visual design that is friendly and inviting. This helps with the initial engagement and sets the tone of 
the course. Create a course that is as visually inviting as possible.

- Provide for multimedia experience. Leverage as much of the multimedia as you can in context. Use all resources to create the best course possible.

- Allow free access. People yearn to be free. A bad experience in e-learning is when the course navigation is locked. Focus on relevant, decision-making scenarios. Don't frustrate them or waste their time with a bunch of extra branched scenarios. Tell them what they need to know.

- Do not test everything. Assessing a person's understanding is an important part of learning, but we do not need to always have a test. In many ways it retards the learning process. As soon as people find out they're being tested, they quit learning and focus on how to pass the test. If you don't need a test, don't include one. If you do need to assess their understanding, perhaps there's a better way to do so.

Specifically since adult are faced with various challenges owing to their physiological and sociological characteristics, they do not operate at the same level therefore learning programmes should be designed with the following characteristics.

- Design a simple e-learning user interface. Avoid complex, non-intuitive navigation. Include "easter eggs' but with caution.. Also, make sure buttons are labeled within the interface, and that the learner has access to simple orientation and navigation instructions that can be reviewed at any time.

- Write using simple, short sentences.

- Add pronunciation guidelines for more challenging words or industry-specific terminology.

- Maximize the use of visuals such as info graphics and relevant stock photos.

- A picture speaks a thousand words and with any audience, imagery helps the message stick.

- Use on-screen text and visuals that support the audio.

$\checkmark$ Let the audio drive the page, while key text and related graphics support the message.

$\checkmark \quad$ Audio should not exactly match the on-screen text.

$\checkmark$ Be sure audio matches with text on screen. Addressing Topic A while the text on-screen focuses on Topic $B$ is a serious error. Two simultaneous messages will result in no message being delivered.

- Provide a supplemental full audio transcript.

An audio transcript allows learners to see the written audio script in case they need to digest the content at their own pace. Be sure to make learners aware of this e-learning course feature as part of the orientation guidelines.

\section{Conclusion}

The development of human capital through open and distance learning in adult education is a key tool for producing a dynamic productive workforce in tandem with international standard in a globalized environment. Formal education in Nigeria alone has not been able to provide the required man power needs. Adult education is therefore needed to increase worker functionality in his working life and enable him cope with the present knowledge trends through the acquisition of appropriate skills. As a principle in adult education, functionality requires lifelong learning to be facilitated through the various adult education programmes with increased access. Therefore the use of e-learning in adult, Open and Distance Learning will help increase the literacy level of the adult population, increase professionalization, increase access to education, improved reading and computer skills, achievement of MDG goals by 2015, sustained life-long learning through individualize self-directed learning and remove the tyranny of space and time.

But certain variables need to be fixed in place and properly controlled, which include regular electricity supply, improved access to the internet through the establishment of internet centers, funding and provision of a viable policy platform with conscious sensitization of the populace.

\section{References}

Adrich, C. (2004). Simulations and the Future of Learning: .San Francisco: Pfeiffer, p.240.

Aroge, S.T. and Hassan, M.A (2006). Labour Education and Actualization of Millennium Development Goals: A Perspective. Adult Education in Nigeria" Journal of NNCAE, 13, 63-76.

Barikor, C.N.(2003). A handbook on distance and open education. Port Harcourt. Sar-el Printers and publishers.

Corneli, J. and Danoff, C. J. (2011) Paragogy. In: Proceedings of the $6^{\text {th }}$ Open Knowledge Conference, Berlin, Germany.

Cross, Jay. (2004). An Informal History of e-Learning. On the Horizon, vol:12, no 3, pp 103-110

Ezimah M.O (2004): Knowing Adult Education; it's Nature, Scope and Processes. Owerri; Springfield Publishers. Federal Republic of 
Nigeria, (2004). National Policy on Education. Lagos: NERDC Press.

Ihejirika J.C and Onyenemezu, E.E (2012). Adult education and development of manpower resources in Nigeria. Academic research international journal. Vol.3.No 3.

Kawawa, R. (1971). Adult Education and National Development, Opening Address delivered at the Third Conference of the African Adult Education Association held at the University of Dares Salaam, Tanzania, April 19th - 24th.

Merrian, S.B.(2001). Andragogy and self-directed learning: pillars of adult learning theory. New directions for adult continuing education. Vol.89, 3-14.

Nwizu S. C.(2001). Evaluation of distance learning education programmes of Nigerian universities. Ph.D dissertation, department of adult education. University of Nigeria,Nsukka.

Ngwu, P.N.C. (2006). The Social Context of Non-Formal Education. Adult Education in Nigeria. Journal of NNCAE, 13, 184 -196.

Nji, A (2000). Creating a Knowledge Society through Distance and Open Learning in Cameroun, in S.A Indabawa, A B. Oduaran, T. Afrik \& S. Walters (Eds.). The State of Adult and Continuing Education in Africa. Windboek: John Meinert Printing

Omolewa, M. A (2000). Setting the Tone of Adult and Continuing Education in Africa. In SA Indabawa, A Oduaran, T. Afrik and S. Walters (Eds.), The State of Adult and Continuing Education in Africa, 11-16, Windhoek: Department of Adult and Non-formal Education, University of Namibia.

Olumukoro, C.O. (2005). The Role of Continuing Education in National Development, Nigerian Journal of Adult Education and Lifelong Learning. 1 (1), 5-56. 
